\title{
Accounting Research and Theory: The age of neo-empiricism
}

\begin{abstract}
The theorising in accounting prior to 1970 was rejected as not providing sufficiently general theories. Informed by theories in economics and finance (and other disciplines such as psychology) and with the aid of computers, attempts to theorise accounting took a new direction. Large data collection and analysis emphasized a purportedly more systematic empirical approach to developing theory.
\end{abstract}

Key words: accounting; neo-empiricism; capital markets research; behavioural finance; efficient markets hypothesis; positive accounting theory

\section{INTRODUCTION}

Around 1970 there was a dramatic change in the approach to accounting research. Several reasons have been suggested for this change in methodological direction by those reviewing the development of accounting thought. To many, a major distinction is a change in direction away from attempts to prescribe a theory of accounting to developing theory from a description of extant practices. To advocates of the latter, previous attempts to develop a theory of accounting were futile as there could never be agreement over many of the inputs into a theory such as the postulates, principles but most specifically the assumptions. Although a very inaccurate description the two approaches are labelled normative (the prescriptive theories that dominated prior to 1970) and positive (the descriptive research that has dominated mainstream accounting research since 1970).

With its emphasis on description, the most defining characteristic of mainstream research since 1970 is its commitment to empiricism. In their book on accounting theory, Henderson, Peirson and Brown (1992) refer to this research as neo-empirical research: a most apt nomenclature. As mentioned, the dominating characteristic was empiricism. It is "neo" (new) because, although earlier research had relied on empiricism in that it sought to establish "theory" from best practice, the emphasis after 1970 was on a more systematic use of empirical evidence. This was largely made possible with the availability of large financial databases to which sophisticated statistical techniques were applied to test hypotheses. This, in turn, was greatly facilitated by the increasing availability and use of computers. 
All neo-empirical accounting research has the underlying assumption of the efficiency of markets - the efficient markets hypothesis (EMH). It is referred to as an "hypothesis" because despite more than forty years of research designed to test the hypothesis all attempts to date have failed to confirm it. Therefore, consistent with the generally accepted process of theory construction which states (simply) that a theory is a confirmed hypothesis, it remains an hypothesis. The EMH emerged in the 1960s from the work of researchers at the University of Chicago trained in economics and finance and working in the areas known as portfolio theory and employing the capital assets pricing model (CAPM). It was then taken up by accountants also working and studying at the University of Chicago and, as stated, it has been the cornerstone of a considerable amount of research over the last forty years. The EMH is an assumption about the relationship of information to security prices. The research area is usually referred to as capital markets research but the EMH has had implications for other research areas as well. Two Australians working at the University of Chicago, Ray Ball and Phillip Brown, are regarded as the first to engage in capital markets research in accounting and their work (Ball and Brown, 1968) has had a vast number of citations. Another seminal work was that by Bill Beaver (1968).

There are various forms of market efficiency which, however, only discriminate on the degree of efficiency similar to how economists describe how perfect a market is: perfect or imperfect etc. Nevertheless, in the literature reference is made to three types of EMH, the strong form (markets very efficient), semi-strong and weak (markets not very efficient). A strongly efficient market would be one in which security prices fully reflect all available information - and do so immediately the information becomes available - all new information is immediately absorbed by the market. A leading figure in the development of the EMH in finance, Eugene Fama, states that a market is efficient if "security prices fully reflect all available information" (1970, p 384). It should be noted that available information will include all information that investors use to make investment decisions and accounting will only be a part of such information.

\section{CAPITAL MARKETS RESEARCH}

Prior to the 1960s the emphasis in finance was on fundamental analysis, That is, attempting to determine a valuation (an intrinsic value) of securities based on past and present financial information (mainly financial statements) and industry and other macroeconomic data. The aim of the analysis was to uncover mispriced securities (in order to take advantage of the mispricing), that is trade in these securities in the knowledge that the prices are not "correct". Employing the new theories in economics and finance, Ball and Brown's study was an attempt to determine the information content (for the securities market) of accounting numbers (in this case income measurements). Through empirical examination of stock market prices Ball and Brown (and later many others) believed they could determine the effect on stock prices of (new) accounting information. Stock prices were taken as objective, external indicators of the usefulness of the information in accounting reports.

Underlying the developments in finance and financial economics, and subsequently accounting, is the notion of portfolio selection; that is, which investments should be made and included in a "portfolio of investments"? In 1959 Harry Markowitz published a book with the title Portfolio Selection: Efficient Diversification of Investments (Wiley \& Sons). Starting from this work, in the mid 1960s two financial economists, Sharpe and Lintner (working at the University of Chicago), developed the CAPM which is designed to determine an appropriate return of a single asset, given a level of risk. 
The notion of risk is an essential element in determining investment. All investment is made at some level of risk. On the assumption that investors are risk averse (they try to avoid risk as much as possible) portfolio theory seeks to determine the appropriate mix of investments that should be held in order to minimize the risk. An investor will undertake a risky investment so long as there is a return sufficient to induce the investment to be made - there is a trade off between risk and return. Both risk and return are crucial elements in the valuation of securities. The expected return from an investment will determine the price an investor is willing to pay but this must be offset by some measure of the risk associated with the investment. At the simplest level, the value of an investment will represent the present value of the expected future dividends from that investment. That is, the expected future dividends will be discounted at a rate of return adjusted for the risk associated with that investment.

Portfolio theory, as indicated, is designed to determine a portfolio of assets. On the other hand, CAPM is designed to provide a measure for a single asset. It does this by comparing the expected return from an asset in relation to a measure of risk $-\beta$ (beta). The beta of a security indicates the riskiness of holding it as part of a thoroughly diversified portfolio; it is the risk associated with a specific asset compared with the average overall market risk.

An assumption of market efficiency is essential to both portfolio theory and CAPM. Accounting research in the 1970s tended to support market efficiency; in the 1980s market efficiency was assumed by researchers; since the 1990s research has found evidence inconsistent with market efficiency (Field et al, p I-280). An underlying assumption of a belief in market efficiency is the economic rationality of investors. With evidence suggesting markets are not rational much recent research has turned attention to the behaviour of investors (who do not necessarily act economically rationally). In 2004 The Wall Street Journal reported that even the "father of EMH", Eugene Fama, at a conference to honour him held at the University of Chicago, conceded that markets may not be efficient and there may be "poorly informed investors" who do not act rationally ${ }^{1}$.

Nevertheless, there are still many accounting researchers who want to believe in market efficiency and undertake research that continues to test for efficiency or assume it exists. Kuhn showed that researchers will continue to believe in a paradigm as a matter of faith despite mounting evidence

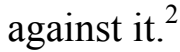

\section{CAPITAL MARKETS RESEARCH AND ACCOUNTING}

Much of the capital markets research in accounting has been in the form of event studies, first used in finance. An event study investigates the association between an information announcement and the behaviour of share prices. As Kothari states:

In an events study, one infers whether an event, such as an earnings announcement, conveys new information to market participants as reflected in changes in the level of variability of security prices as reflected in the changes in the variability of security prices or trading volume over a short time period around the event (2002, I-116)

There are also association studies which Kothari says are

. . . tests for a positive correlation between an accounting performance measure (eg earnings of cash flow from operations) and stock returns . . . (2002, I-116)

\footnotetext{
${ }^{1}$ The Wall Street Journal, Monday, 18 October, 2004

${ }^{2}$ A more cynical interpretation could be that people who have built their not insignificant careers on the basis of commitment to paradigm have a lot to lose if they later reject it.
} 
Most studies have been one or the other but Ball and Brown's (1968) study is both. It provides evidence that there is information content in accounting earnings announcements and correlates the signs of the abnormal stock returns in the period of an earnings announcement.

There has been a considerable amount of capital markets research in accounting over the last forty years. The studies can be classified according to the researchers' motivation as Kothari (2002. p I-121) has done ${ }^{3}$. Although there is considerable overlap among the areas he has listed them as:

(i) methodological capital markets research,

(ii) evaluation of alternative accounting performance measures'

(iii) valuation and fundamental analysis research,

(iv) tests of market efficiency, and

(v) value relevance of disclosures.

As its name implies, methodological capital markets research is concerned with examining the significance and relationship of various variables when trying to determine the relation between security returns and financial statement information. For example, questions that related to items such as the information content of additional information or alternative measures, the effects of governance structures in respect of the amount and timing of company information releases and other matters, are of interest to researchers.

In evaluating alternative accounting measures, researchers are concerned with perceived deficiencies in some existing performance measures. The term quality of earnings has often been used in relation to this type of capital markets research most of which are association studies.

As noted above, much of the research in finance prior to the $1970 \mathrm{~s}$ has been termed fundamental analysis. However, there has been a considerable body of capital markets research in accounting and finance that attempts to incorporate a more systematic empirical analysis of the information in investigating the problems of valuation and this is the third of Kothari's classifications. Underlying it is the fundamental value assumption, viz, that the value of equity is equal to the present value of future expected dividends. Fundamental analysis research is undertaken to try and identify mispriced securities (as earlier). It does this by comparing an "intrinsic value" of a security to the "market value". Because of the fundamental assumption it follows that this type of research is heavily dependent on forecasting. For example, what will be the future flows of cash, revenues and expense? The research includes financial modelling and a good example is that by Feltham and Ohlson. It is discussed at length by Beaver (2002) who argues that it is an excellent example of an attempt to provide an accounting theory. As such it has led to considerable empirical research as researchers have attempted to provide empirical support for the model.

Also as indicated previously, market efficiency is a necessary assumption in almost all accounting (and other) capital markets research. Research first supported efficiency but later research has cast doubt on it. Considerable research effort has been directed to testing market efficiency. As

\footnotetext{
${ }^{3}$ Kothari (2002) provides an excellent survey of capital markets research and it is not possible here to cover the field as thoroughly. Those wishing to have a fuller picture of this research should refer to his work. There are other summaries with slightly different classifications (eg Beaver, 2002) but, generally speaking, they cover the same material. Kothari's work is part of a full summary of mainstream accounting research published in two issues of the Journal of Accounting and Economics in 2001, the proceedings of that journal's conference of 2000. Those interested in pursuing an understanding of mainstream accounting research are referred to this material.
} 
research results threw doubt on the EMH researchers introduced corollary assumptions in an attempt to "save" the explanatory power of the EMH. These were usually referred to as anomalies; for example, if prices tended to rise at the end of the days trading it was referred to as the "day-end effect" and research to support this would examine stock market in the very short term - intra-day trading - in search of patterns or "regularities". So many anomalies have been uncovered that researchers in finance have tended to reject the EMH. Many accounting researchers, however, have attempted to retain it as it directly impacts on the interpretations that can be placed on observed associations between security prices and accounting numbers (cf Beaver, 2002). In fact, as Lee clearly states, "The degree to which markets are efficient affects the demand for accounting research in investment decisions, regulatory standard-setting decisions, performance evaluations, and corporate disclosure decisions" (2002, I-234).

The EMH is useful to capital markets researchers who are interested in examining the effect of new information releases. For example, Ball and Brown's (1968) study was concerned with the effect on security prices of income announcements and they found a sufficiently high correlation to declare support for EMH. However, subsequent studies questioned this conclusion because they found that abnormal returns continued after a profit announcement suggesting that the new information was not fully incorporated into the security prices. This is referred to as the post-earnings announcement drift and research in this area became an important sub area of capital markets research in attempt to explain this anomaly. The post-earnings announcement drift anomaly is just one of many unresolved issues in respect of market efficiency ${ }^{4}$. Lee inquires: Why do we believe markets are efficient? And he responds that:

The answer boils down to a visceral faith in the mechanism of arbitrage. We believe markets are efficient because we believe arbitrage forces are constantly at work. (2002, p I-236)

Lee's response is somewhat paradoxical in that if markets are efficient then arbitrage is not possible. To him arbitrage is "information trading aimed at profiting from imperfections in the current price" (2002, p I-236). Generally speaking arbitrage is taking advantage of different prices of an asset in different markets; thus, information trading aimed at exploiting (overall) market imperfections.

Many capital market research studies seem more appropriate to the disciplines of finance or financial economics than accounting. However, a recent form of this research attempts to investigate the association of specific accounting variables and security prices. It seeks to enable researchers to predict how accounting variables relate to the market value of equity. It has attracted the name value relevance research and an "accounting amount is defined as value relevant if it has a predicted association with equity market values" (Barth et al, 2002, p I-79). Value relevance research has become popular since the early 1990s. Its exponents claim the essential concerns with this type of research are the qualitative characteristics of relevance and reliability. Value relevance research is different to other capital market research in that it requires the researcher to have a very a sound knowledge of accounting and its institutional setting. It attempts to determine whether accounting numbers relate to value in the predicted manner. Underlying it is a valuation model so it could be argued that the research is only as good as the valuation model adopted. For example, some use the balance sheet as the basis for valuations. This is surprising for research for more than fifty years has questioned balance sheet figures as representing any "value". Nevertheless, value relevance research employing the balance sheet model assumes that the market value of the equity is equal to the market value of severable assets

\footnotetext{
${ }^{4}$ Those interested in pursuing this topic are recommended to read Beaver's (2002) or Kothari's (2002) papers.
} 
less the market value of liabilities; hence the name, the balance sheet model. The market value of the component whose incremental association is being assessed is separated from the other items in order that the research can determine the "value relevance" of that item.

An alternative to the balance sheet model is an earnings model which, for example, could regress stock returns on alternative measures of earnings and the regression with the highest $\mathrm{R}^{2}$ is considered the best performance measure or most value relevant (cf Holthausen and Watts, 2002, p I-56). There are, however, some problems with this research. Generally, they concern the reliance on accounting numbers to construct the valuation model (see Holthausen and Watts, 2002 or Beaver, 2002, p 464). For example, there are problems associated with the reported measure of income or earnings, such as accounting conservatism. In addition, some items affect retained earnings but are not included in the income statement. Where this happens it is referred to as a "dirty surplus" as opposed to the situation in which all changes in retained earnings are reflected in the income statement (a "clean surplus" policy). To Holthausen and Watts value relevance is of very limited relevance to standard setters (as implied in the title of their paper).

Barth et al (2002), who have undertaken many value relevance studies, have countered some of the criticism. First, they contend that it provides fruitful insights into questions of interest to standard setters who, secondly, have a primary focus on equity investment and are interested in the usefulness of items of information provided to the equity market in financial statements. Third, extant valuation models of valuation can be used despite their often simplifying assumptions. Fourth, conservatism in the accounts is not a problem for value relevance research and can in fact be one of the items for which tests are undertaken. Fifth, although relevance and usefulness are fairly synonymous, the latter is illdefined so value relevance research does not test for usefulness. And, finally, there are econometric techniques that can be employed to overcome any problems in the method.

As Beaver has commented, "value relevance research is controversial" (2002, p 460). Nevertheless there are many well-known researchers engaged in this form of research. They have investigated many reported accounting numbers and issues. For example, pension accounting, nonfinancial intangible assets and even footnote disclosures. As such it may, as Beaver has suggested, be able to assist define and describe accounting issues and lead to some sort of (accounting) theory. Like other forms of capital markets research it is dependent on market efficiency but it examines questions with respect to valuation differently. It may (Barth et al, 2002) or may not (Holthausen and Watts, 2002) assist regulators in formulating appropriate accounting standards.

Market efficiency is essentially about the ability of the "market" to incorporate information about investment decisions. The "market" is made up of many economic actors. Some are individuals trading on security markets in their own right or through advisers and brokers and some are institutional investors with substantial investment divisions. Assisting in investment decision are those individuals known as financial analysts, those with expertise in analysing financial and other information that can be used in making investment decisions. On the basis of their analysis analysts make forecasts on which some investors depend. A major area of accounting research is investigating analysts' behaviour to uncover the reasons why particular forecasts are made as these forecasts become part of the information available to the market. As Beaver states, "Efficient analysts' information processing can facilitate the efficiency of security prices" (2002, p 464). Much of the research has suggested that analysts' forecasts are optimistic. One cynical reason for this uncovered in the 1990s was that some analysts were being compensated for "talking up" particular investments. However, the research 
examines analysts' behaviour to determine how and why they arrive at their conclusion, how reliable this information is and what elements of financial statement information do they find important.

\section{NOISY TRADING}

In an efficient market security price movements are like a random walk. That is, investors cannot predict what new information might result in changes in security prices which will respond over time unpredictably - randomly. However, in a strongly efficient market investors will absorb any new information instantaneously and the market will respond accordingly. The actual price of a security will be an estimate of the intrinsic value. Logically, it would not really be worth trading as no one could "beat the market". However, trading does occur. Efficient markets believers responded by weakening the assumptions of a strong market to one in which it could be claimed that markets were semi-strong. As indicated, this has been a fundamental assumption (i.e. market efficiency) of accounting capital markets research. Considerable research energy has been devoted to demonstrating (or saving) market efficiency but the evidence has been mounting against it.

Neimark has suggested that developments in accounting research mirror developments in the broader academy but "lag behind other fields" (1990, p 103). She did not have belief in capital markets in mind but her contention seems to be appropriate to capital markets research. Researchers in finance and financial economists have generally accepted that markets are not efficient yet many accounting researchers persist with it: to them, as Lee (quoted above) has suggested it is a "gut feeling". An essential assumption of the EMH is that investors act in an economically rational manner - there is rational behaviour.

There has been mounting evidence that many investors do not act as rationally as believed; they, in fact, act (economically) irrationally. Accordingly, there has been a distinction drawn between "smart-money" investors and noise (or liquidity) traders. The former trade on the basis of fundamental information - they utilize the information available quickly and in an unbiased manner. On the other hand, noise traders act on signals that ultimately prove to be "value-irrelevant"; for example unsubstantiated rumours. It has been found that there is a very significant amount of noise trading and it is probably responsible for the volatility in realized returns. As noise trading is irrational, it is not possible to statistically or mathematically model it, which has direct implications for much accounting research.

\section{BEHAVIOURAL FINANCE}

Another financial economist working at the University of Chicago in the same department as Fama was Richard Thaler. He has long disagreed with his colleague about market efficiency. He has argued that markets are not efficient and that investors respond in an unpredictable and so-called irrational manner. Such a view gave rise to a new way of researching finance and it is called behavioural finance in which the emphasis is on the study of investor behaviour. Investors' nonrational behaviour has the potential for creating problems for markets. Thaler and others for some time noted the anomalies in markets which contradicted market efficiency. For example, they noted that although the EMH held that investors would only respond to new information trading continued without any new information and prices fluctuated irrespective of any new information. Just because markets are unpredictable (cf random walk) it does not mean that markets are efficient.

The shift away from the belief in market efficiency to behavioural finance has implications for how markets are regulated and corporate governance issues which in turn have flow on effects for 
accounting research. For example, the value relevance research seeks to aid accounting regulators by examining the market's response to specific items of accounting information. If markets are not efficient then it would be virtually impossible to make any predictions based on this type of research. However, some researchers such as Lee finds that, despite some unresolved issues in behavioural finance, "capital market research is an exciting place to be at the moment" (2002, p I-234). To him, there is considerable potential for accounting researchers so long as researchers "unshackle" themselves "from the notion that price is equal to value" (p I-253).

\section{POSITIVE ACCOUNTING THEORY}

At the start of this paper it was pointed out that a distinction is made between what is referred to as normative and positive theorising. This is a distinction that has been made by economists to describe theories based on description and those based on prescription. It is believed that a positive statement is a statement about what is and that contains no indication of approval or disapproval. A normative statement expresses a judgment about whether a situation is desirable or undesirable and is couched in terms of what should be or ought. On the basis of this distinction there has been a considerable body of accounting research that has claimed to be positive. Actually, the capital markets research discussed above could probably all be described as positive. It is claimed that the research prior to the 1970 research direction shift was normative. It is a little simplistic to suggest that statements can be categorized as purely positive or purely normative because underlying all statements are unseen assumptions. Similarly, as will be demonstrated later, to classify theories as positive or normative is equally simplistic.

Positive accounting theory (PAT) is an expression of neo-classical economic theory. Fundamental to it is a belief in rational choice theory. That is, material self-interest - usually referred to as opportunistic behaviour - is the basis of all economic activity. Therefore, in PAT self-interest (opportunistic behaviour) is the reason for the choice of accounting methods and techniques and policy decisions. In PAT the firm (organisation, company or whatever ${ }^{5}$ ) is described in terms of a collection of contracts - a nexus of contracts. Contracts are necessary in order to get self seeking individuals to agree to cooperate. For example, contracts with managers, suppliers of capital and employees (including the managers). The contracts are necessary to get individual parties to act to maximise the wealth of the owners (shareholders). However, there will be contracting costs associated with the contracts, for example, costs of negotiating with and maintaining and monitoring the performance of the parties involved. PAT holds that firms will seek to minimise the contracting costs and this will affect the policies adopted, including the accounting policies.

There is a difference between positivist and positive but positive theories are clearly a form of positivist theorising. Therefore, PAT holds to most of the tenets of positivism. Accordingly, the aim of theorising is examination, description, explanation and control (prediction). There are three hypotheses around which PAT's predictions are organised, viz, the bonus plan hypothesis, the debt covenant hypothesis and the political cost hypothesis.

\footnotetext{
${ }^{5}$ In most of the research in this area reference is made to the firm. However, for a more general understanding the terms firms, organisations and companies are used interchangeably While this may not be entirely accurate it is sufficiently so for the present purposes - most firms are in fact corporations. Similarly, the terms owners and shareholders are used to represent the principals in agency relationships for the same reason. Also, managers would be the ultimate decision makers in the firm and they report directly to the board of directors who represent the shareholders' interest. Thus the mangers are the agents of the owners. This is a simplification as the situation of corporate governance is a complex issue and will be more fully expanded upon in subsequent papers.
} 
The bonus plan hypothesis suggests that managers of firms will be more likely to choose accounting procedures that shift reported earning from future periods to the current period. To understand the need for this hypothesis it is necessary to note that one of the theories underlying positive accounting research is agency theory.

\section{Agency Theory}

Agency theory is an important part of PAT. It has its origins in the information economics literature in which information is placed into an explicit decision-making setting. That is greater information leads to better decisions. However, agency theory extends traditional information economics in that it recognises that several forces are at play in organisations that affect how it operates. For example, the notion of information asymmetry is a problem that impacts on resource allocation issues. There is information asymmetry when some parties (managers) have greater information than others (for example, investors). Therefore will manger disclose this additional information to the "market"? Agency theorists believe there has to be incentives for managers to make additional (voluntary) disclosures.

An agency relationship exists where one party (a principal) delegates some decision making authority to another party (the agent). The principal and the agent will enter into a contract that recognises the relationship. According to PAT both parties will act in their own self interest which will not necessarily coincide. The classic example of this sort of agency relationship is that between the shareholders and the managers of a company. Shareholders will be interested in maximising their wealth; the manager will want to maximise his or her rewards from managing the firm (material financial and perquisites, "reputation" as a good manager and other factors). A principal-agent relationship exists between the shareholders (principal) and the manager (agent). Agency costs will be incurred by the principal to monitor the behaviour of the agent to ensure the agent operates in the best interest of the principal. Much of these monitoring costs will involve accounting. For example, a good example of a monitoring cost is the cost incurred in a financial audit.

On the other hand, the agent will also incur costs to bond himself or herself to act in a manner that serves the interest of the principal. These are referred to as bonding costs and preparing regular (say, quarterly) financial reports to the owners is an example. These are costs of the agent in that there are the time and effort involved in preparing these reports and the constraints that such reporting place on any potential opportunistic behaviour of the agents.

A third type of cost is identified as a residual loss which will result because, despite the monitoring and bonding costs incurred, the interests of the principal and the agent will still not be fully aligned - the agent does not always act fully in the principal's interests which will result in some unaccounted for costs, that is, residual costs.

Research studies in agency theory have uncovered different types of opportunistic behaviour by agents. These include excessive perquisites, empire building, shirking and incorrect investment decisions. Perquisites are the "little extras" that managers surround themselves with such as a luxury office, business trips, entertainment and the like. Empire building is increasing the sphere of responsibility which will result in greater "personal satisfaction" and possible greater remuneration. Shirking is a rather blunt expression to describe the behaviour of mangers who do not "work the full day" - for example, long lunches or over delegation of duties and responsibilities. The fourth example 
of opportunistic behaviour is slightly more complex. Basically it involves a difference in the risk aversion between the owner and the agent. The manager may be less willing to engage in high risk-high return investments as it increases the likelihood of the loss of a job in cases where the investment "fails".

\section{Debt-Holders and Owner-Managers}

The second hypothesis in PAT, referred to above is the debt-covenant hypothesis. To understand this it is first necessary to know what is meant by a debt covenant. These arise in a contract between a firm and its debt providers. The firm agrees to refrain from activities that may increase the debt providers' risk. Some examples would be not, without the debt provider's approval, to sell assets or raise additional finance (that may affect the debt provider's claims against the assets in the firm), or pay excessive dividends. There are many other instances where the activities of the firm would not be in the interests of the debt providers so there would be an agreed debt covenant.

The debt covenant hypothesis in PAT is that, other things being equal, the closer a firm is to violating an accounting-based debt covenant, the more likely the owner-manger is to select accounting procedures that shift reported income from a future period to the present period. Any increase in (current) reported income would reduce the likelihood of a technical covenant default. Examples of such accounting-based covenant restrictions may relate the debt to equity ratio, the level of working capital, interest coverage ratios and other similar measures. Remember, however, that PAT assumes opportunistic behaviour, so covenants will usually include the basis on which such measures are made because often there are slight (and some not so slight!) variations in how certain accounting measures are derived. Therefore, an example of a contracting cost would be the cost of an external audit of the accounting numbers.

A complicating factor in the debt covenant hypothesis relates to who the managers are. If there is a separation of ownership and management then there is an extra agency relationship to be considered. Consequently, in research to test the hypothesis the case of the owner-manager has often been assumed so as to make it easier to understand why opportunistic behaviour occurs. In addition, the form of debt is a significant factor, for example whether it is public debt or private borrowing (for example, see Cotter, 1999)

\section{Political Costs}

The third PAT hypothesis is the political cost hypothesis. This suggest that, other things being equal, the greater the political costs faced by a firm, the more likely the mangers will choose accounting procedures that defer reported income from current to future periods. This hypothesis introduces the idea of political implications into accounting policy choice. Some factors attract political attention for some reason or other. For example, in 2005 (and well before) Telstra invoked considerable political attention as the Australian Government was contemplating selling its shares in the company. Although much of the political attention was on the level of service to be provided to rural Australia some accounting policy decisions came to light such as the company having paid dividends from its reserves. This could impact on the ability of the company to invest in new technologies that could affect the service it could provide to rural Australia customers.

Therefore, this hypothesis of PAT draws attention to the fact that not all policy decisions (including accounting) adopted by a firm will be based on purely economic considerations. When banks announce record profits there will be public pressure on the government to examine their 
customer charges. Petrol prices are very susceptible to public attention and in 2004 and 2005 the companies that were the leading profit companies (in countries around the world) were oil companies. It lead in some countries to special taxes being imposed on petroleum companies who then (in countries were it was legal, such as the USA) switched to LIFO inventory valuations which would lead in turn to lower recorded profits and, therefore, lower taxes. Many firms because of their sheer size attract political attention from a variety of "public watchdogs". For example, in Australia there is the Australian Competition and Consumer Commission (ACCC) charged to ensure "fair and competitive" trading policies by companies.

\section{PAT Research}

Although there had been references to the need for positive accounting research earlier it was popularised in the late 1970s by Watts and Zimmerman (eg 1978). Since that time there has been a tremendous research output which claims to be positive. As indicated above, the earlier neo-empirical accounting research fits the description of being positive but it is popularly believed that only research since the late 1970s is positive. Watts and Zimmerman, in their earlier work, drew heavily on developments in economics and finance and the EMH and other neo classical assumptions underlie positive accounting. As Kothari explains, the development of

positive accounting theory involves the accounting implications of the

concurrent theoretical developments in finance and economics. Watts and Zimmerman

then tailored those theories to explain accounting phenomena. (2002, pp I-115-116)

Much of PAT research has focussed on the motives of management in making accounting choices when markets are semi-strong (in a strong form market accounting loses its relevance as the market is aware of all information) and there are significant costs in drawing up and enforcing contracts as well as political costs arising out of the regulatory process. The research is often referred to as accounting choice research because the emphasis is on explaining why managers make accounting method changes, given the three hypotheses discussed above. There has been a slight change in emphasis is some PAT research. Originally, PAT researchers assumed choice was made on opportunistic grounds decisions were based on self interest. Some later researchers contended that often choices were made on efficiency grounds. That is, managers may choose a particular accounting method because it better reflects what they believe to the underlying economic reality. The majority of positive accounting studies have concentrated on determining post contracting opportunistic behaviour and uses ex post data, that is, it assumes managers choose policies after the fact. Other studies assume choices are made before the contracting in order to present a more efficient picture of the firm (say, to a potential lender); choices are made ex ante (before the fact) (cf Healy and Palepu, 2002, p I-418).

The aims of PAT research were clearly set out in early papers by its major initial exponents, Watts and Zimmerman. These aims were summarised by Zimmerman (1978) as he reviewed some earlier research and compared PAT with that earlier research. He claimed that PAT sought to "explain the world in which we live". As such it attempts to provide answers to why certain accounting methods are chosen over others, and why (the then) regulation of accounting was left in the hands of the profession rather than by direct government involvement. Zimmerman claimed that PAT was essential in identifying the affected parties in question of accounting choice and policy.

Watts (1995) claimed that PAT research was an application of the methodology of the sciences (especially those used in economics and behavioural sciences) to investigate accounting phenomena. Therefore it was designed to explain (provide reasons for why accounting takes the form it does) and 
predict (how accounting changes across time and place). Although a wide range of economic and behavioural sciences are used, early PAT research drew heavily on financial economics (finance) for theoretical support. This then extended to other economic theories. A key claim by PAT adherents is that research prior to PAT did not possess an objective function that was not independent of subjective preferences. What this means is that the objective function of a theory prior to PAT derived an objective function subjectively; as a result of a value judgement. For example, what is the objective of accounting? Some argued for economic efficiency, some for investor protection and so on. There is, PAT adherents argue, no way to establish the correctness of the choice. However, neither can a PAT theory! As indicated early PAT research was based on the assumption of opportunistic behaviour and later the assumption of desired efficiency. Thus, neither pre-PAT nor PAT theories can establish an objective function objectively (cf Zimmerman, 1978, p 610). But, implicit in PAT adherents' claim is that, unlike the pre-PAT theorists, they are objective.

\section{THE CRITIQUE OF NEO-EMPIRICAL RESEARCH}

As indicated above, there has been a tremendous amount of neo-empirical research undertaken and the results dominate certain journals. Thus, this research has been labelled mainstream research. There has, however, been a substantial amount of criticism of this mainstream research. Much of this criticism has been directed at PAT research although the tenor of the criticism applies to all neoempirical research. This criticism is at all levels from the underlying ontological assumptions to the research methods employed. It is assumed here that research is undertaken to either generate new theories of support existing theories. Therefore, the criticism of neo-empirical research can be discussed in terms of how theory is affected.

Ontologically neo-empirical research adopts a strong realist position and this determines the epistemology and methodology employed. Methodologically it is positivist or modernist meaning that it is committed to employing the method of the physical science. Consequently, it is strongly rooted in an empirical epistemology. The method is the hypothetico-deductive methodology. However, this description, although accurate, has to be treated with caution as the advocates and supporters of PAT research do not always use terms and concepts consistently. In fact, an early critic, Christenson (1983), argues that Watts and Zimmerman in their early advocacy of PAT have totally misunderstood many epistemological and methodological issues. Godfrey et al (2003), strong supporters of PAT, first argue for the importance of falsificationism in (all) research ( $p$ 270) then later agree with a suggestion in the literature that falsificationism is inappropriate for PAT ( $\mathrm{p} 353$ ).

PAT derives its name from economics, specifically two economists, John Neville Keynes (writing in 1891) and Milton Friedman, neither of whom referred to positive theory but rather positive science. Keynes was echoing a sentiment popular in the $19^{\text {th }}$ Century regarding positive statements which contributed to positivist science. Friedman took up the idea of positive science being concerned with "what is" but his theorising is best described as instrumentalism, in which theories are useful only as instruments for generating successful predictions about observables. PAT theorists claim to only admit statements of "what is" which suggests that they are clearly aligned with positivism (which holds a hard line on this matter) and not instrumentalism (which accepts a slightly more liberal view that such statements are necessary and useful but not always able to be established). Therefore, despite its origins with Friedman's neo-classical economics, it seems that PAT adopts a stricter positivist view than his instrumentalist one. This is borne out by their insistence on the belief that they are truly scientific (eg Watts, 1995, p 297; Zimmerman, 2002, II-418 - the leading exponents of PAT). 
The epistemological foundation of PAT is empiricism - that all knowledge is derived from sensory experience. There are problems with a purely empirical epistemology and it has generally been rejected by philosophers of science. Christenson (1983) describes some of the problems. Knowledge cannot be derived from pure empiricism as it will have to be described in a language and use concepts which must be a priori (cf the attempt by Nelson to denigrate some research by describing it as a priori - discussed in Gaffikin, 1986). However, the most significant practical problem is the problem of induction. This is the belief in the uniformity of nature (phenomena) and is based on past observations. In other words, an inductivist argues that he or she will be able to make predictions based on knowledge derived from past observations. This presumes things remain the same such that the past observations are a guide to the unobserved things in the past and the future but the presumption is only based on (past) observed phenomena. Hence the reasoning is circular: we justify reliance on induction by relying on induction. However, in respect of science, Popper claimed this did not matter because the method of science was hypothetico-deductive. This, is to start with an hypothesis and a set of conditions, deduce what follows from them and then test the conclusions to determine whether they are in fact correct. For example, start with the proposition that iron is heavier than water from which it can be deduced that iron would sink in water. This can be then be tested and if iron sinks in water then the hypothesis is confirmed (verified). However, in practice it is not as straightforward as this as there are often many assumptions involved and there are always questions about the testing, including the problem of induction. As it is often not possible to observe every instance there is always some doubt. To overcome this Popper introduction the notion of falsification which holds that so long as a statement is falsifiable then it can be part of scientific theorising. An example of a falsifiable statement is profit announcements do not affect share prices. An example of a non-falsifiable statement is share prices either respond to or ignore profit announcements. In the first case it is easy to prove or disprove the statement; in the second case the statement is couched in such as way so as to make it impossible to prove or disprove.

It is difficult to avoid the conclusion that PAT is in fact not a theory but a methodological prescription. Zimmerman has given a clear statement of what PAT advocates believe a theory is:

Succinctly stated, a theory explains what has been observed, tests empirically the hypothesis derived from the theory, and then predicts what is yet to be observed. (2002, pp II 417-8)

He then proceeds to quote Hempel, who along with Popper, is the leading exponent of the hypotheticodeductive process. However, he draws some seemingly contradictory conclusions. For example, he suggests that "testing hypotheses derived from theory allows knowledge to accumulate"; "Theories seek to explain systematic regularities"; and "Theories suggest hypotheses that help guide scientific investigations") p II-418). Normally it is claimed by hypothetico-deductivists that hypotheses lead to theories. He agrees with Hempel that without hypotheses data collection is blind but Zimmerman is suggesting a circular process which seems to lead him to the same difficulty as the problem of induction yet he claims that "theories make predictions about facts that have not yet been collected"!! Theories do not make predictions; predictions are used to test a theory. In Popper's terminology, the explanans (the initial hypothesis and the conditions), are tested by serious attempts to falsify them and where they remain unfalsified this results in the theory. This, Zimmerman illustrates by stating that given the notion of random walk behaviour of stock prices, together with "principles from economics" enabled the EMH to be deduced. As indicated above, EMH has been subjected to a variety of tests and the great bulk of evidence suggest that the EMH has been falsified. Yet many PAT and other researchers in accounting seem to ignore this fact and continue to operate on the basis that EMH is an 
established "theory". Zimmerman may not be confused about the definition and place of theory but his description certainly is.

\section{THE SOCIO-POLITICAL CRITIQUE OF PAT}

The above has attempted to demonstrate that there are many unanswered technical and philosophical problems with much neo-empirical, especially PAT, research. Despite these problems many researchers are still committed to PAT and claim to be engaged in appropriate accounting research. Kuhn suggested that continued adherence to a way of thinking (he used the word paradigm) was ultimately a matter of faith. However, there are probably many sociological and political explanations for this faith. The history of human knowledge contains very many examples of where sociological and political power have caused ideas to remain when logic, reason and "evidence" would show otherwise. For example, the Christian church for many years persisted with beliefs such as the Earth being the centre of the universe when researchers such as Galileo Galilei demonstrated that in fact the Earth revolved around the Sun as part of a much greater universe. The power and ideology of the Church enabled it to maintain its position despite the evidence to the contrary. Galileo was forced to recant (retract his words) or be burned at the stake. Some would suggest that many accounting researchers in US business schools, with an ideological commitment to maintaining neo-classical economic dogma, are the modern day equivalent of the medieval Church in maintaining "knowledge" which preserves an ideology even though it has been demonstrated to be mistaken!

As with any theory, underlying neo-empirical and PAT research are assumptions. Zimmerman (above) has alluded to some of these as "principles of economics" by which he means the assumptions upon which neo-classical economics rests. These include, economic rationality - resulting in opportunistic behaviour - a view that holds that all action is driven by the desire to maximise wealth. This is a core assumption for other assumptions such as the free operation of unfettered markets and, consequently, the possibility of efficient markets. It is extended to firms which are said to organise themselves in the most efficient manner to maximise the chances of their survival.

PAT advocates have been very successful in maintaining it as the dominant force in accounting research. They have done this by exercising power to shape the discipline of accounting (research). They have changed the old adage of knowledge is power to power is knowledge - they have strategically defined PAT as the only form of worthwhile accounting knowledge. In order to do this they have exercised various political and other techniques such as language.

Watts (1995, p 299) has described one reason for the shift towards neo-empirical and positive accounting research in the late 1960s and early 1970s. This is the fact that US business schools were encouraged by industry groups and corporations to engage in more "business oriented" research and to make greater use of the "underlying disciplines". This call was backed up by resource support (more than \$US30 million in grants). It is reasonable to infer from this that business wanted accounting research that supported business enterprise - to justify their activities. By underlying disciplines it seems they were referring to economics and finance which were already imbued with a strong business (capitalist) ideology (such as neo-classical economics).

As the wealth of developed economies has increased over the last fifty years there has increased interest in economic and financial matters. Such interests have been brought into everyday living and economic metaphors have become part of everyday language. It is difficult to see that accounting has greatly influenced this as the advent of PAT research seemed to signal greater concern with 
methodological issues rather than everyday practical concerns. A great many accounting articles addressed esoteric theoretical issues rather than problems facing the practicing arm of the profession. As Lee suggests, "Too many academic studies read like chain letters to other academics" (2002, p I247). There was a wholesale rejection of all research that did not fit the prescribed PAT pattern. Journal editors acted as gate keepers and refused to publish non PAT research papers. This may be excusable in privately sponsored journals specifically set up to publish such research (eg Journal of Accounting and Economics) but it happened even in the journal of the major academic accounting body, The Accounting Review ${ }^{6}$, and, later, in the Canadian academic journal (Contemporary Accounting Research) and the Australian counterpart (Accounting and Finance) as well as other outlets in other parts of the world. This is one illustration of the power that can be exerted by specific interest groups. It is an attempt to create and shape "a discipline"; those who do not conform to the prescription are marginalised or "excluded".

Rhetoric is a linguistic device by which people persuade others to their point of view. PAT supporters have subscribed to the rhetoric of a particular economic ideology. Mouck (1992) has written on how PAT advocates have employed rhetorical devices to convince others that theirs is the only way to accounting truth. The rhetorical devices they use, Mouck suggests, are appeals to the authority of science, including "economic science", claims to being the only neutral way to knowledge and the disparagement of alternative views.

There is a strong belief in Western societies that science sets the standard for intellectual rigour and this partly explains why those engaged in disciplines of social concern choose the title social science. Despite considerable evidence that indicates otherwise, many in economics believe Lazear's statement that "economics is the premier social science" (quoted in Zimmerman, 2002, p II-423). PAT advocates continually claim to be scientific largely because they "rely on economics-based theory" (Zimmerman, 2002, p II-423). PAT derives its scientific status through economics unaware that many economic thinkers have rejected the claim to the status of science because they realise it is quite inappropriate.

Equally misguided are the claims by PAT advocates that they are neutral in their research. They do this because since the time of Plato objectivity has been held as a desirable aim of reliable knowledge. Obviously PAT researcher are making value judgements in deciding what are researchable problems, what is relevant evidence and how this is to be incorporated into their conclusions. This is the second rhetorical device Mouck argues that is used by PAT advocates. This topic was addressed early in the development of PAT research by Tinker, Merino and Neimark (1982).

The third rhetorical device Mouck claims is employed in PAT is the disparagement of alternatives: the campaign of a "strategy of vilification" and efforts to "degrade and stigmatize the opposition" (quoted in Mouck, 1982, p 51). This has included emphasising the distinction between normative and positive research and claiming that normative researchers were not "scientific" (see "The Decline of Normative Theorizing" in Watts, 1995, p 300). This incorrect assertion has been picked up and popularised without question by some textbook writers (eg Godfrey et al, 2003) who make claims such as "They (PAT critics) fail to provide a competing theory which has superior explanatory or predictive power" while ignoring the near total failure of PAT to impact on the practice of accounting. Such is the power of rhetoric on a susceptible community!

\footnotetext{
${ }^{6}$ This is well detailed in a whole book devoted to this issues: Tinker, T and T Puxty (1995), Policing Accounting Knowledge, the Market for Excuses Affair, Princeton, Markus Wiener Publishers.
} 
Neo-empirical researchers use other rhetorical devices such as the narrative of emancipation. By this, is meant the call to researchers to free themselves from the impossible constrictions of past research which sought truths such as true income and to merely concentrate on description which would lead to new hypotheses and theories. As Watts claims:

One difficulty with the normativist alternative is that there are an unlimited number of possible functions that accounting might fulfil . . . (1995, p 301)

The implication is that by engaging in PAT the researcher is freed from the "impossible search" among all the alternative functions presumably to one which supports the dominant economic ideology.

\section{CONSEQUENCES}

This paper has described a major shift in the research approach in accounting that took place around 1970. While still modernist in the claim of being scientific it differed from previous research in some of the assumptions and the research methods. While some of this new research has provide insights into the possible use of accounting in economic analysis it has raised many problems to which it has been unable to respond intellectually. There has been considerable evidence refuting one its most basic assumptions, that markets operate efficiently $(\mathrm{EMH})$. There is also evidence refuting many other assumptions employed in this new research (eg CAPM). There are technical difficulties such as how to interpret the evidence (Healy and Palepu, 2002, p I-419). There are methodological inconsistencies and misunderstanding (such as those raised by Chritenson, 1983). There are question of the sociological assumptions (economic rationality). However, despite all these problems this new research continues to dominate the academic accounting world at the expense of alternatives making accounting different from other closely associated disciplines (see the Presidential Address to the American Accounting Association's Annual Meeting in San Francisco, August, 2005).

This domination has been possible because of the power contained and exercised by a certain group of accounting institutions. While a positive consequence of this power has been the flowering of research in accounting academe, the negative aspects are in the control they exercise in denying the discipline accounting research which is different to theirs. That is, it must comply with their prescription which is strangely inconsistent with their commitment to description as opposed to prescription.

\section{REFERENCES}

Ball, R and P Brown (1968), “An Empirical Evaluation of Accounting Numbers”, Journal of Accounting Research, v 6, pp 159-177.

Barth, M, W H Beaver and W R Landsman (2002), "The relevance of the value relevance literature for financial accounting standard setting: another view", in Kothari et al, pp I 77-104.

Beaver, W H (1968), “The Information Content of Annual Earnings Announcements", Journal of Accounting Research, Supplement, v 6, pp 67-92.

Beaver, W H (2002), "Perspectives on Recent Capital Market Research", The Accounting Review, v 77, pp 453-474.

Christenson, C (1983), “The Methodology of Positive Accounting”, The Accounting Review, v 58, pp 1-22.

Cotter, J (1999) "Asset Revaluations and Debt Contracting", Abacus, pp 268-85.

Fama, E (1970), "Efficient Capital Markets: A Review of Theory and Empirical Work”, Journal of Finance, v 25, pp 383417.

Fields T D, T Z Lys and L Vincent (2002), "Empirical Research on Accounting Choice”, in Kothari et al, pp I $255-307$.

Gaffikin, M J R (1986), "Legacy of the Golden Age: Recent Developments in the Methodology of Accounting", Abacus, March.

Godfrey, J, A Hodgson and S Holmes (2003), Accounting Theory, (5 ed), Milton, John Wiley \& Sons Australia Ltd. 
The Australasian Accounting Business \& Finance Journal, February 2007

Gaffikin: Accounting Research and Theory: the age of neo-empiricism. Vol. 1, No.1. pp. 1-17.

Healy, P M and K G Palepu (2002), "Information asymmetry. Corporate disclosure, and the capital markets: A review of the empirical disclosure literature', in Kothari et al (2002) pp I 405-440.

Henderson, Scott, Graham Peirson and Rob Brown (1992), Financial Accounting Theory, Its Nature and Development, Melbourne, Longman Cheshire.

Holthausen, R W and R L Watts (2002), "The relevance of the value relevance literature for financial accounting standard setting", in Kothari et al (2002), pp I 3-75.

Jones, S, C Romano and J Ratnatunga (eds) (1995), Accounting Theory: a contemporary review, Sydney, Harcourt Brace

Kothari, S P (2002), "Capital markets research in accounting", in Kothari et al (2002), I 105-231.

Kothari, S P, T Z Lys, D J Skinner, R L Watts and J L Zimmerman (2002), Contemporary Accounting Research, Synthesis and Critique, Amsterdam, Elsevier Science BV.

Lee, C M C (2002), "Market efficiency and accounting research: a discussion of 'capital market research in accounting' by S P Kothari", in Kothari et al (2002), pp I 233-253.

Markowitz, H M (1959) Portfolio Selection: Efficient Diversification of Investments, New York, John Wiley

Mouck, Tom (1992), "The Rhetoric of Science and the Rhetoric of Revolt in the 'Story' of Positive Accounting Theory", Accounting, Auditing and Accountability Journal, pp 35-56.

Neimark, M (1990), "The King is Dead, Long Live the Dead”, Critical Perspectives in Accounting, pp 103-114

Tinker, T, B Merino and M Neimark (1982), "The Normative Origins of Positive Theories: Ideology and Accounting Thought", Accounting, Organizations and Society, v 7, pp 167-200.

Watts, R (1995), "Developments in Positive Accounting Theory" in Jones at al pp 297-353.

Watts, R and J Zimmerman (1978), "Towards a positive theory of the determination of accounting standards", The Accounting Review, v 53, pp 112-134.

Zimmerman, J L (1978), "On the 'Statement on Accounting Theory and Theory Acceptance' ", Proceedings of the 1978 American Accounting Association Meeting, pp 606-622.

Zimmerman, J L. (2002) in Kothari et al (2002), Contemporary Accounting Research, Synthesis and Critique, Amsterdam, Elsevier Science BV. 